SHS Web of Conferences 10, 00037 (2014)

DOI: $10.1051 /$ shsconf/20141000037

C Owned by the authors, published by EDP Sciences, 2014

\title{
Insomnia management for ageing employees with job stress
}

\author{
I. Roja ${ }^{1}$, Z. Roja ${ }^{2}$, and H. Kalkis ${ }^{3}$ \\ ${ }^{1}$ Riga Eastern Clinical University Hospital, Latvia \\ ${ }^{2}$ University of Latvia, Ergonomic Research Center, Latvia \\ ${ }^{3}$ Rīga Stradiņš University, Latvia
}

\begin{abstract}
In Latvia, the number of aging employees suffering from sleep disorders caused by job stress and poor sleep hygiene is increasing. The non-pharmacologic and pharmacologic treatment is prescribed for these employees in the sleep management. The aim of this research is to clarify the efficiency of using psychotherapy with learning and observing sleep hygiene, combined with the melatonergic drug during a six-week treatment course applied to 25 both male and female intellectual workers over 65 years suffering from insomnia caused by job stress. For the patients representing Group "A" cognitive hypnotherapy, intervention for improving coping with job stress and usage of the melatonergic drug was prescribed, while Group "B" patients received six weeks only drug. The severity of depressive episodes in employees was measured by MontgomeryÅsberg Depression Rating Scale, the level of anxiety was assessed by use Rosenberg SelfEsteem Scale. The results of the research show that insomnia patterns disappeared for $75 \%$ of women and $80 \%$ of men employees in Group A, but in Group B individuals, - only for $20 \%$ of women employees. The results acquired let concluding that the six-week treatment - cognitive hypnotherapy combined with melatonergic drug - is an effective treatment for aging workers suffering from sleep disorders.
\end{abstract}

\section{Introduction}

Each year, in March, the World Sleep Day is organized by the World Association of Sleep Medicine and many insomnia specialists. An occupational health doctors, during their conferences on sleep disorders, report this problem as global epidemic making the life quality of young and aged employees decrease due to chronic sleep problems (Culebras, 2012). In modern assessment of work environment insomnia is considered as an urgent ergonomic risk factor nowadays. Workers with chronic insomnia who are too sleepy to fully function on the job also cost in many countries serious financial loss each year, according to a nationwide survey (Landsbergis, 2003; Daley et al., 2009). Special attention and importance is put to preventive actualities in the topical management of insomnia: elimination of psychosocial ergonomic risks in the work environment (distress, irregular working hours, night duty and night work for aging employees without medical examination, poor personal sleep hygiene, alcohol and nicotine consumption, etc.). In psycho-bio-social approach short-term psychotherapy is used in the treatment of these employed individuals, namely, in the form of cognitive hypnotherapy sessions during which there develops psychophysical relaxation and traumatic events caused by job stress, negative stereotypes of

This is an Open Access article distributed under the terms of the Creative Commons Attribution License 4.0, which permits unrestricted use, distribution, and reproduction in any medium, provided the original work is properly cited. 


\section{SHS Web of Conferences}

behavior and patterns of insomnia are being healthy processed. In the new pharmacological approach applied to these patients also melatonergic drug is included in the combined treatment helping to synchronize circadian rhythms, to prevent dysfunction of hippocampus and to decrease depressive mood (Graci et al., 2007; Rancans et al., 2009).

Over the last two years of our study 25 male and female subjects aged between 65 and 73 years - professionally responsible intellectual workers suffering from chronic insomnia, depressive mood during the daytime, anxiety with palpitations, sweating and turbulent feelings before sleep were examined and treated. Psycho-traumatizing conflict situations at work, irregular working hours, night shifts, poor sleep hygiene were stated to be the cause of sleep disorders. According to Classification of Diseases and Health Problems these disorders with insomnia as a symptom fall under the classification of nonorganic, emotional sleep disorders in the section F51.9 (ICD-10, 1996).

\section{The aim of the research}

The aim of the research was to assess the effectiveness of the use of cognitive hypnotherapy and melatonergic drug, antidepressant Valdoxan applied in the six weeks combined therapy course for employed persons over 65 years of age suffering from chronic emotional sleep disorders.

\section{Materials and methods}

For 25 patients (15 women, 10 men, professionally responsible intellectual workers, average age: $69.44 \pm 2.43$ ) complaining about chronic insomnia, anxiety and depressive mood during the last year, the insomnia algorithm was determined and insomnia survey (Kessler et al., 2004) was done. Before the beginning of the treatment course, workers were divided into groups A and B having regard of the individual agreement with combined treatment of insomnia (non-pharmacologic and pharmacologic) or only - with pharmacologic treatment.

The criteria for the patients to be included in the research were: neurosomatic and psychosocial assessment of the patient; duration of sleep disorders - more than a month; sleep disorders resulting from negative stress at work and negative stereotypes of behavior and patterns of insomnia; withdrawal from usage of sleep aids with benzodiazepine and non-benzodiazepine structure, barbiturates; personal consent to the course of treatment and active involvement. Exclusion criteria, in their turn, were: hypersomnia or spastic daytime sleepiness, somnambulism, narcolepsy, sleep apnea, hypnologic hallucinations, nightmares, sleep disorders caused by psychiatric or somatic illness (schizophrenia, organic nervous disorders, chronic pain, restless leg syndrome, cardio-respiratory failure, nocturia, etc.), liver and kidney problems, addictions, side effects of medications.

Before starting the six weeks combined treatment course, hypnotic susceptibility of Group A patients ( $\mathrm{n}=15,10$ women and 5 men) were evaluated using the Sunnen Trance Scale (STS; Sunnen, 1988). From the first day of treatment course Group A patients received medication therapy (MT) - melatonergic antidepressant Valdoxan: $25 \mathrm{mg}$ tablet - before night sleep, combined with cognitive hypnotherapy (CHT), the length of one hypnotherapeutic session -45 minutes, twice a week. Patients' individual desire for CHT and MT or MT only, confidential therapy - was the dominant principal when choosing a particular treatment for a particular individual.

Each Group A patient received a compact disc (CD) with psychotherapeutic indications to perform mind-body relaxation exercises at home, to cope with job stress and to master appropriate sleep hygiene. Group B patients $(\mathrm{n}=10,5$ women, 5 men) received six weeks only MT - Valdoxan: $25 \mathrm{mg}$ tablet - before bedtime. When starting the course of treatment, patients of both groups were acquainted with sleep hygiene rules and made aware of the need to abstain from alcohol and nicotine during the treatment course. The meaning of Sleep Diary (SD) was explained for patients of both groups and it was recommended to keep it on a daily basis during the treatment and three months after the 
Int. Conf. SOCIETY. HEALTH. WELFARE.

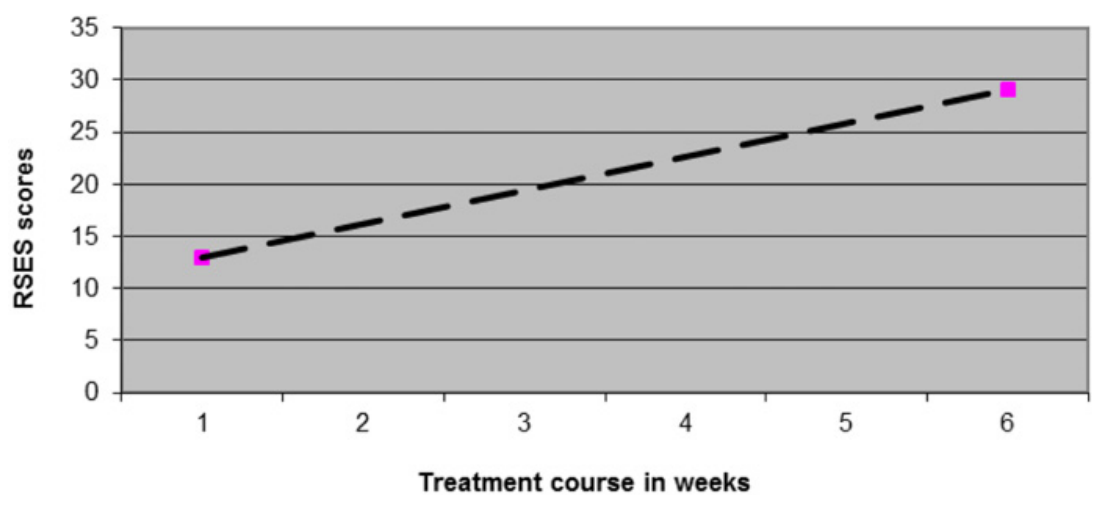

Figure 1. The most characteristic changes in the level of anxiety and self-esteem during the treatment course for Group A patients according to Rosenberg Self- Esteem Scale (RSES).

treatment course. To assess the alert level for Group A and B patients Rosenberg's Self-Esteem Scale (RSES) was used (Rosenberg, 1989). A stage of depressive mood in ageing employees with chronic insomnia was investigated by modified Montgomery- Åsberg Depression Rating Scale (MADRS Montgomery and Åsberg, 1979). Follow-up data were collected after 3 months.

Results acquired during clinical trials were processed with the computer using Excel software and statistical data processing program SPSS.11 according to standard descriptive statistical methods, the significance level $p$ was assessed (Landis et al., 1977).

\section{Results}

As the result of the six week treatment course combining cognitive hypnotherapy and melatonergic medication, antidepressant Valdoxan, learning sleep hygiene by use CD in order to develop healthy sleep patterns, insomnia patterns (depressive mood during the day and somatoform disorders before sleep: impetuous feelings, palpitations and sweating) disappeared for Group A patients - women (75\%) and men $(80 \%)$.

The most characteristic changes in the level of anxiety and self-esteem for Group A patients, assessing the results according to RSES, are shown in Figure 1 and Table 1.

Analysis of RSES and MADRS data for Group A and B ageing both sex intellectual workers suffering from chronic emotional insomnia showed that, at the beginning of the treatment course, $80 \%$ of Group A patients and $80-100 \%$ Group B patients had a low self-esteem, depressive mood during the day, manifest anxiety, somatoform disorders before sleep, caused by psycho-traumatizing events in their work environment, deficient social support and a poor individual sleep hygiene. At the end of the treatment course and three months after the course, during follow-up examination, statistically significant increase of self-esteem was stated, anxiety, depressed mood, and somatoform disorders before sleep disappeared for 75\%-80\% of Group A patients and only for 20\% of Group B patients.

None of the 11 Group A patients ( 7 women and 4 men) 3 months after the combined treatment course took either Valdoxan or other sleeping aids. 9 Group B patients (4 women and 5 men) - continued to use Valdoxan or other sleeping aids.

During CHT sessions, the Group A patients were confronted in their imagination with the psychotraumatizing work situation (storyline development, self-revelation, strengthening) and their stress level increased during various CHT storyline moments. Stress level decreased or stabilized when the distress was processed in a healthy way (during CHT sessions individuals were able to meet fearlessly with the scary past events, to experience emotional catharsis, to meet with themselves in positive situations of 


\section{SHS Web of Conferences}

Table 1. The results for Group A and B patients according to chosen methods.

\begin{tabular}{|c|c|c|}
\hline Methods & Beginning of the treatment course & $\begin{array}{l}\text { End of the treatment course, } \\
3 \text { months after treatment course during } \\
\text { follow-up }\end{array}$ \\
\hline $\begin{array}{l}\text { Sunnen Trance Scale } \\
\text { (STS) }\end{array}$ & $\begin{array}{l}\text { Group A: } 9 \text { women }(90 \%, \mathrm{n}=10), \\
3 \text { men }(60 \%, \mathrm{n}=5)- \\
\text { good imagination, good dissociation } \\
\text { and psychophysical relaxation skills; } \\
\text { women }(\mathrm{n}=10) \text { and men }(\mathrm{n}=5)- \\
\text { no contraindications to CHT }\end{array}$ & - \\
\hline $\begin{array}{l}\text { Montgomery-Åsberg } \\
\text { Depression Rating } \\
\text { Scale (MADRS) }\end{array}$ & $\begin{array}{l}\text { Group A: } 8 \text { women }(80 \%, \mathrm{n}=10), \\
5 \text { men }(100 \%, \mathrm{n}=5)-25 \text { items. } \\
\text { Group B: } 4 \text { women }(80 \%, \mathrm{n}=5), \\
5 \text { men }(100 \%, \mathrm{n}=5)-25 \text { items. }\end{array}$ & $\begin{array}{l}\text { Group A: } 7 \text { women }(70 \%, \mathrm{n}=10), \\
4 \text { men }(80 \%, \mathrm{n}=5)-7 \text { items. } \\
\frac{\text { Group } B: 4 \text { women }(80 \%, \mathrm{n}=5), 5 \text { men }}{(100 \%, \mathrm{n}=5)-15 \text { items. }}\end{array}$ \\
\hline $\begin{array}{l}\text { Rosenberg's Self - } \\
\text { Esteem Scale (RSES) }\end{array}$ & $\begin{array}{l}\text { Group A: } 8 \text { women }(80 \%, \mathrm{n}=10), \\
4 \text { men }(80 \%, \mathrm{n}=5)-\text { less than } 15 \\
\text { points. } \\
\text { Group B: } 5 \text { women }(100 \%, \mathrm{n}=5) \text {, } \\
4 \text { men }(80 \%, \mathrm{n}=5)-\text { less than } 15 \\
\text { points. }\end{array}$ & $\begin{array}{l}\text { Group A: } 7 \text { women }(75 \%, \mathrm{n}=10), \\
4 \text { men }(80 \%, \mathrm{n}=5)-20 \text { or more points } \\
\text { Group B: } 1 \text { woman }(20 \%, \mathrm{n}=5)-20 \\
\text { points; } 4 \text { women }(80 \%, \mathrm{n}=5), 5 \text { men } \\
(100 \%, \mathrm{n}=5)-\text { less than } 15 \text { points. }\end{array}$ \\
\hline Sleep Diary (SD) & $\begin{array}{l}\text { Group } A: 7 \text { women }(70 \%, \mathrm{n}=10), \\
4 \text { men }(80 \%, \mathrm{n}=5)-1 \text { point } \\
3 \text { women }(30 \%, \mathrm{n}=10), \\
1 \text { man }(20 \%, \mathrm{n}=5)-2 \text { points } \\
\text { Group } B: 5 \text { women }(100 \%, \mathrm{n}=5), \\
3 \text { men }(60 \%, \mathrm{n}=5)-1 \text { point, } 2 \text { men } \\
-2 \text { points }(40 \%, \mathrm{n}=5)\end{array}$ & $\begin{array}{l}\text { Group A: } 9 \text { women }(90 \%, \mathrm{n}=10), 4 \\
\text { men }(80 \%, \mathrm{n}=5)-3 \text { points, } 1 \text { woman } \\
(10 \%, \mathrm{n}=10), 1 \text { man }(20 \%, \mathrm{n}=5)-2 \\
\text { points. } \\
\text { Group } B: 1 \text { woman }(20 \%, \mathrm{n}=5)-3 \\
\text { points, } 4 \text { women }(80 \%, \mathrm{n}=5)-1 \text { point, } \\
5 \text { men }(100 \%, \mathrm{n}=5)-1 \text { point. }\end{array}$ \\
\hline
\end{tabular}

their lives at work). The study was carried out in accordance with principles of Ethics and empathic communication between the doctor and the patient.

The data acquired using STS, showed a higher hypnotic susceptibility for female patients (90\%) in comparison to male patients $(60 \%, \mathrm{p}=0.01)$ before the treatment was started, no contraindications to CHT in Group A. These results are in correlation with the information recorded in Group A females' Sleep Diaries (SD) (80\%) compared to records of men patients (40\%) regarding the rising of the level of personal "I" and self-esteem as the result of psychotherapy and self-relaxation trainings and learning and observing appropriate sleep hygiene; high quality work activities during the day after having had a healthy night's sleep, new possibilities to fix working hours, to participate in improvement of psychological climate of one's work environment.

During the first hypnotherapeutic communication session, Group A patients were inspired to learn sleep hygiene in order to develop healthy sleep patterns (the text of suggestion was recorded on CD used by patients between CHT sessions at home and after the hypnotherapeutic treatment course): Your personal comfortable bed in the ventilated room is destined only for sleep and sexual activities; 3-4 hours before going to bed you do not take strong tea, coffee, alcohol and nicotine; you have managed to give up the harmful habit: to watch TV, eat and work in bed: to read and work using your laptop; you go to bed always at the same time - when you feel sleepy; if you cannot fall asleep within 15-20 minutes - you get up, take peaceful, relaxing exercises and listen, if you want, to a quiet, pleasant music, then again - you lie back in bed, shut your eyes, relax - watching in your imagination and feeling how your body gradually gets rid of the tension.

The analysis of Group A and B patients' records in the sleep diaries was performed (all patients completed the SD daily in the morning and in evening): $90 \%$ assessed their feeling with "1": I feel 


\section{Int. Conf. SOCIETY. HEALTH. WELFARE.}

tired; episodic palpitations, sweating, and alert before night's sleep, total sleep duration in the nigh $\mathrm{t}=$ 0-1-2 hours. In the evening the alcohol use was reported "in order to get rid of depressive mood during the day resulting from psycho-traumatizing situations at work": Group A -7 women $(70 \%, \mathrm{n}=3)$, 3 men $(60 \%, n=5)$, Group B -3 women $(60 \%, n=5), 2$ men $(40 \%, n=5)$. In the evening and at night, during the day - use of coffee, strong tea, nicotine: Group A - 7 women $(70 \%, \mathrm{n}=10), 5$ men $(100 \%, \mathrm{n}=5)$, Group B -3 women $(60 \%, \mathrm{n}=5), 4$ men $(80 \%, \mathrm{n}=5) .80 \%$ of Group A patients and $70 \%$ of Group B patients informed in their diaries of a habit already for years: TV watching, smoking, eating, and working with laptop while in bed. Only 4 Group A patients $(26 \%, n=15)$ and 2 Group B patients $(20 \%, \mathrm{n}=10)$ reported on a practice of having a short walk in fresh air before sleep. 5 Group A patients $(33 \%)$ and 2 Group B patients $(20 \%)$ reported a habit - to have a nap during the day. Night duty and night work without medical examination for ageing women and men who work during night time before they start night work was stated to be the observable cause of sleep disorders in 5 Group A patients $(33 \%)$ and 5 Group B patients (50\%).

The results obtained by processing SD data in the beginning of the treatment, lead to conclusion that older intellectual workers, regardless their gender - had neglected personal sleep hygiene, and both women and men had developed certain patterns of insomnia.

Analysis of SD data at the end of the treatment and after its conclusion for both groups of patients assessed by follow-up examination data were as follows: Group A: 9 women $(90 \%, \mathrm{n}=10), 4$ men $(80 \%, \mathrm{n}=5)-3$ points (fully awake, having slept well), Group B - only 1 woman -3 points (20\%, $\mathrm{n}=5$ ). Patients recorded such relevant patterns of high-quality night's sleep: not taking strong tea, coffee, alcohol and nicotine, TV watching, eating and working with laptop while in bed has become unacceptable; no depressive mood during the day; palpitations, sweating, and impetuous feelings before sleep have disappeared. A stereotype of going to bed at the same time has developed. Total duration of sleep time during the night: 7-8 hours, the number of waking-up times: 1-2 during the treatment course and 1-2 times within three months after the treatment course. There is no desire and no need to have a nap during the day.

In the fifth week of the treatment Group A patients used Valdoxan: $25 \mathrm{mg}$ - before bedtime - only 2 times a week; during the sixth week - once a week; after the treatment course - not using. While taking Valdoxan, 1 woman in Group A experienced a side effect - dizziness, 1 man and 1 woman in Group B - headache. 7 patients of Group B parallel to treatment course - according to their records in the SD - continued to drink strong tea or coffee at night, smoked, and didn't give up a habit of working with laptop while in bed.

Evaluation of follow-up examination data showed that 10 Group A females - didn't change jobs, continued to perform professionally responsible tasks and already during treatment course such females did not tend to cope with their problems alone: they demanded their legal rights, consulted trade union representatives and achieved extermination of negative stress at the workplace. According to their records in the SD after treatment course - insomnia was considered as an urgent ergonomic risk factor in their work environment. 2 Group A males, 4 Group B females and 4 Group B males - had changed jobs and performed less professionally responsible tasks without psycho-traumatizing stress at work.

\section{Discussion}

The results of the research coincide with the literature data regarding the role of short-term psychotherapy and melatonergic drugs in the combined treatment of working individuals suffering from insomnia caused by multifactorial and individual symptoms (Morgenthaler, 2006; Brzezinski, 2005).

The results of the research coincide also with the literature data concerning the harmful effects negative stress in the work environment, behavior and lifestyle habits have on the health of elderly people (Ancoli-Israel and Ayalon, 2006), as well as concerning the importance of insomnia management (Roja et al., 2009). The results of the research prove the effectiveness of cognitive hypnotherapy in healthy 


\section{SHS Web of Conferences}

processing of psycho-traumatizing event processing and developing of healthy night's sleep pattern, as well as importance of regular self-suggestion using a $\mathrm{CD}$ with hypnotic suggestion indications at home after working day for both sex individuals over 65 years suffering from chronic emotional sleep disorders.

For working individuals over 65 years suffering from insomnia of inorganic nature (difficulty of falling asleep, waking up early, depressed mood at work during the day) during cognitive hypnotherapy sessions - an "internal sleep clock image" was created and strengthened in action. This image evokes at night sleep in one's brain and throughout the body and allows to enjoy this healthy sleep until the morning comes, as well as individual "I" was strengthened, creating new ways of thinking and behavior stereotypes necessary after having experienced psycho-traumas at work. Instead of the old insomnia pattern night's sleep patterns of high quality were strengthened emphasizing individual's personal ability to observe proper sleep hygiene during the treatment and after it, to refuse from using sleeping aids, alcohol and nicotine. The effectiveness of these suggestions during hypnotherapeutic sessions is in line with the acknowledging the efficiency of special scenarios in patients sleep management basing on clinical evidence-based cognitive hypnotherapy (Graci and Hardie, 2007; Alladin, 2008).

\section{Conclusions}

The six-week non-pharmacologic and pharmacologic treatment course of insomnia - combination of cognitive hypnotherapy and melatonergic drug with antidepressant effect from the first day of treatment course - is an effective adaptive short-term therapy for working intellectual workers of both sex over 65 years suffering from chronic emotional sleep disorders and depressive mood caused by job stress, deficient social support and a poor individual sleep hygiene Before starting the treatment course insomnia inquiry should be made and the insomnia algorithm must be set by use insomnia algorithms and insomnia questionnaire. It is very important is to perform clinical examination, as well as to test subjective well-being, to keep sleep diary, to use CD to practice self-relaxation and to observe sleep hygiene.

Learning sleep hygiene during integrated treatment course in order to develop healthy sleep patterns in aging employees linked up with medical examination for particular individuals who work at workplace during night time before they start night work were stated to be the observable assessment of such employee.

Such treatment with psycho-bio-social approach should be included in the management of chronic insomnia, stress and anxiety for working aging women and men.

\section{References}

[1] Alladin, A. (2008). Cognitive Hypnotherapy. John Wiley \& Sons, Ltd 294 pp.

[2] Ancoli-Israel, S., Ayalon, L. (2006). Diagnosis and treatment of sleep disorders in older adults. Am.J.Geriatr. Psychiatry, 14 (2), 95-103.

[3] Brzezinski, A., Vangel, M.G., Wurtman, R.J. (2005). Effects of exogenous melatonin on sleep: a meta-analysis. Sleep.Med.Rev. 9 (1), 41-50.

[4] Culebras, A. World Sleep Day. (2012). Annual event highlights ventilatory disturbances. Newsletter "World Neurology". USA, Rockville, MD, 7.

[5] Daley, M., Morin, C.M, LeBlanc, M., Gregoire, J.P., Savard, J. (2009). The economic burden of insomnia: direct and indirect costs for individuals with insomnia syndrome, insomnia symptoms, and good sleepers. Sleep, 32, 55-64.

[6] Graci, G.M., Hardie, J.C. (2007). Evidenced-based hypnotherapy for the management of sleep disorders. The International Journal of Clinical and Experimental Hypnosis. Taylor \& Francis Group, USA, Philadelphia, 55 (3), 288-302. 
Int. Conf. SOCIETY. HEALTH. WELFARE.

[7] International Statistical Classification of Diseases and Related Health Problems, Tenth Revision (ICD-10). (1993). Geneva, World Health Organization.

[8] Kessler, R.C., Ustun, T.B. (2004). The World Mental Health (WMH) Survey Initiative Version of the World Health Organization (WHO) Composite International Diagnostic Interview (CIDI). Int. J. Methods Psychiatr. Res. 13, 93-121.

[9] Lacks, P. (1988). Daily sleep diary. In Hersen, M., and Bellack, A.S. (eds). Dictionary of Behavioral Assessment Techniques (pp. 162-164). New York: Pergamon.

[10] Landis, J.R., Koch, G.G. (1977). The Measurement of Observer Agreement for Categorical Data. Biometrics, 33, 159-174.

[11] Landsbergis, P. (2003). The changing organization of work and the safety and health of working people: a commentary. J. Occ. Environ. Med 45, 65-72.

[12] Montgomery, S.A., Åsberg, M. (1979). A new depression scale designed to be sensitive to change. British Journal of Psychiatry, 134, 382-389.

[13] Morgenthaler, T., Kramer, M., Alessi, C. et al.(2006). Practice parameters for the psychological and behavioral treatment of insomnia: an update. Sleep, 29, 1415-1419.

[14] Rancāns, E., Zārde, I. (2007). Cirkadiānie ritmi psihiatrijā [Circadian Rhythms in Psychiatry]. Žurnāls ārstiem un farmaceitiem Latvijā "Doctus" [Journal for Physicians and Pharmaceutists in Latvia "Doctus"], lpp. 35-38 (in Latvian).

[15] Roja, I., Roja, Ž., Zalkalns, J. (2009). Miega traucējumu menedžments [Management of the sleep disorders]. Žurnāls ārstiem "Medicine" [Journal for physicians ”Medicine”]. Rīga, jūnijs-augusts, lpp. 37-38 (in Latvian).

[16] Rosenberg, M. (1989). Society and the adolescent self-image. Middletown, CT, England: Wesleyan University Press. Revised edition, 147-150.

[17] Sunnen, G. (1988). Medical Hypnosis in the Hospital. Advances. Journal of the Institute for the Advancement of Health, 5 (2), 18-24. 